University of Nebraska - Lincoln

DigitalCommons@University of Nebraska - Lincoln

Faculty Publications of the Center on Children, Families, and the Law

Children, Families, and the Law, Center on

2010

Emotional Abuse and Controlling Behaviors in Heterosexual

Relationships: The Role of Employment and Alcohol Use for

Women and Their Partners

Egbert Zavala

Kansas State University, egbertz@ksu.edu

Ryan Spohn

University of Nebraska - Lincoln, rspohn@unomaha.edu

Follow this and additional works at: https://digitalcommons.unl.edu/ccflfacpub

Part of the Family Law Commons

Zavala, Egbert and Spohn, Ryan, "Emotional Abuse and Controlling Behaviors in Heterosexual Relationships: The Role of Employment and Alcohol Use for Women and Their Partners" (2010). Faculty Publications of the Center on Children, Families, and the Law. 14.

https://digitalcommons.unl.edu/ccflfacpub/14

This Article is brought to you for free and open access by the Children, Families, and the Law, Center on at DigitalCommons@University of Nebraska - Lincoln. It has been accepted for inclusion in Faculty Publications of the Center on Children, Families, and the Law by an authorized administrator of DigitalCommons@University of Nebraska - Lincoln. 


\title{
Emotional Abuse and Controlling Behaviors in Heterosexual Relationships: The Role of Employment and Alcohol Use for Women and Their Partners
}

\author{
Egbert Zavala and Ryan E. Spohn \\ Department of Sociology, Anthropology, and Social Work, \\ Kansas State University, Manhattan, Kansas, USA
}

Corresponding author - Egbert Zavala, Department of Sociology, Anthropology, and Social Work, Kansas State University, 204 Waters Hall, Manhattan, Kansas 66506, USA; email egbertz@ksu.edu

\begin{abstract}
The purpose of this study is to examine the role of economic resources, status compatibility, and alcohol consumption on forms of nonphysical abuse, such as controlling and emotional abuse. Specifically, we focus on the connections between women's employment, the employment of their partners, alcohol use, and women's risk of abuse in intimate relationships. We hypothesize that women in intimate relationships with men will experience more emotional abuse to the extent that they are economically vulnerable. Moreover, abuse should increase if their employment status, in relation to that of their partner, challenges the man's marital power. Moreover, alcohol use by women and/or their partners is also predicted to be associated with emotional abuse. We find some support for assertions that socioeconomic deprivation, as well as challenges to men's masculinity, is associated with emotionally abusive male partners. However, the prevalence and amount of alcohol use by the male partner stands out as the most consistent predictor of emotional abuse in heterosexual relationships.
\end{abstract}

Theory and research on intimate partner violence has undergone a number of refinements and expansions. Particularly, scholars of domestic violence have documented the complex nature of abusive relationships, including physical, emotional, and controlling abuse, eco- 
nomic maltreatment, or any combination of these acts (Strauchler et al. 2004; Outlaw 2009). Early studies utilizing the then-newly created Conflict Tactics Scale (Straus 1979) focused on physical violence (i.e., slapping, punching, kicking, etc.), that did not encompass other forms of violence including emotional abuse, threatening physical harm, and attempting to control a partner's behavior (Dobash and Dobash 1979; DeKeseredy 1995, 2000; Loring 1998; Felson and Messner 2000; Kaukinen 2004; Strauchler et al. 2006; Johnson 2006). Lack of research on these latter topics can largely be contributed to the ways in which scholars first defined terms such as domestic violence and intimate partner violence. For example, defining these incidents as simply physical acts perpetrated against an intimate partner fails to capture other abusive acts, such as the verbal, mental, and emotional abuse that victims endure in abusive relationships (Loring 1998; Kaukinen 2004; Demaris and Kaukinen 2005; Carbone-López et al. 2006; Stark 2007; Outlaw 2009). Because emotional abuse often exists along with other severe forms of violence, there is still more to be learned about how emotional and controlling abuse is used in intimate relationships.

The use of nonphysical violence in abusive relationships is well established in the literature (Strauchler et al. 2004; Margolin et al. 1998; Kaukinen 2004; Felson and Messner 2000; Outlaw 2009; Schwartz 2005). We argue, however, that research on emotional abuse and controlling behaviors can be advanced by simultaneously examining factors such as employment compatibility and alcohol consumption by both the offender and the victim. Studies have documented that the composition of the relationship makes certain women prone to violence when compared to other forms of relationships. For example, studies by Kaukinen (2004) and Macmillan and Gartner (1999) documented that women who were in marriages that threaten the traditional male identity as the primary financial provider (i.e., the wife is making more money than her husband) were more likely to experience physical and emotional abuse than women whose husbands were the primary breadwinner (i.e., the wife is not working or made less money). Although both studies highlighted the importance of employment status between couples, MacMillan and Gartner (1999) encourage us to further explore this connection using a sample of women in the United States. Because both studies used a sample of Canadian respondents, we should be careful about assuming that studies on intimate violence in Canada automatically apply to couples in the United States. Furthermore, research has already established that chronic alcohol users are frequent victims of physical, sexual, and emotional abuse (Rice et al. 2001). A recent 
study has found that alcohol use by both victim and the perpetrator can increase violence between partners in heterosexual relationships (Roudsari et al. 2009). We follow their lead by examining alcohol consumption of both the victim and the offender in hopes of providing a more complete understanding of the role alcohol plays along with employment in predicting emotional and controlling behavior. Specifically, we argue that interactions between the alcohol use of the offender and the victim will produce the most accurate portrayal of the role this substance plays in abusive relationships.

The purpose of this study is to examine the role of status compatibility and alcohol consumption on controlling and emotional abuse. Alcohol consumption might best be viewed by sociologists as a control variable when relating employment situations to abusive acts. In this role, we believe a closer look at alcohol use by both the offender and victim is warranted in order to discern the true, causal impact of employment on emotional abuse (in other words, to avoid omitted variable bias in regression analyses). We argue, however, that the role of alcohol use and abuse is interesting in its own right as we develop a more thorough understanding of the causes of this phenomenon. In the literature review that follows, we examine the literature on common precursors of emotional abuse and then focus more closely on the primary variables of interest: employment patterns and alcohol consumption.

\section{PRECURSORS TO EMOTIONAL ABUSE}

\section{Economic Deprivation and Abuse}

The question of social class, economic deprivation, and their role in intimate partner violence has often been examined, with research generally finding that economic deprivation is linked to higher rates of violence towards women (Peterson and Bailey 1992; Tolman and Raphael 2000; Leone et al. 2004). For example, analyzing evidence from the National Crime Victimization Survey, Greenfeld and colleagues (1998) and Rennison (1999) found that the poorest women had rates of violence almost eight times as high as women in the highest income level. Some research indicates that intimate partner violence is also positively associated with a person's economic dependence (see Tolman and Raphael 2000 for a review).

Though several major studies indicate that more physical violence exists in lower-income families (Greenfeld et al. 1998; Rennison 1999; Cunradi et al. 2002), the presence of emotional abuse in these relationships is 
somewhat less clear. We hypothesize, however, that emotional abuse will exhibit a similar relationship. Because controlling and emotional abuse is often an antecedent to physical assaults in intimate relationships (Hamby and Sugarman 1999; Felson and Messner 2000; Salari and Baldwin 2002), and women reporting lower socioeconomic status than that of their partners report higher rates of violence (Macmillan and Gartner 1999), we predict that emotional and controlling abuse will also be negatively related to economic status. In other words, factors such as employment and educational achievement will buffer women from abusive relationships.

Minority racial status might also increase vulnerability to emotional abuse. For instance, examining controlling behavior in intimate relationships, Stets (1995) suggests that males from minority groups may be more likely to attempt to control their partners. Arguing that members of minority groups are relatively powerless members of society who feel they cannot control their environment, Stets (1995) suggests that minorities are more likely to control their partners in order to achieve control they would otherwise not experience. On the other hand, it is possible that higher victimization rates among minority women might simply be due to their lower average socioeconomic status (see Leone et al. 2004; Frias and Angel 2005). Moreover, these predictions become inordinately confusing in the presence of mixed-race couples. As a result, our analysis of the effect of race in the context of emotional abuse among intimate partners will be exploratory in nature.

\section{Patriarchy and Status Incompatibilities}

Examining the role of male power and control in intimate relationship increases our understanding of the causes and consequences of male-tofemale physical violence. Intimate partner violence is part of a systematic pattern of control and dominance over women and is not exclusive to men who have more income and social status than their female partners (Kwesiga et al. 2007). Testing the idea that a lack of power and dependence increases vulnerability to emotional abuse is necessary to understand the link between gender inequality and emotional abuse and controlling behavior (Hamby and Sugarman 1999). Due to the paucity of research on this topic, it is important to examine whether predictors of emotional abuse differ according to the relative status of partners.

Our theoretical framework for analyzing the relative socioeconomic status of partners is founded on an understanding of patriarchy as a social system. In his discussion of the impact of patriarchy in our society, Al- 
lan Johnson (2005) argues that patriarchy is based on the idea that women and men have profoundly different basic natures. Specifically, men were made in the image of a masculine God, which places them higher than women in the cultural, social, political and economic hierarchies.

In describing the impact of this system, Johnson (2005) suggests that patriarchy is something that we participate in, analogous to a game. As such, he states that interactions in a patriarchal social system will differ significantly from those in a matriarchal or egalitarian system, and these differences will be evident to the observer even in the absence of clear knowledge of the "personal characteristics or motivations" of the individual actors in the system (2005, p. 34). In comparing a patriarchal social system to a game of Monopoly, Johnson suggests that people may find themselves, when enmeshed in such a system, behaving in ways that might be disturbing in a different context. Whereas the game of Monopoly might bring to light unusually greedy tendencies, patriarchal systems can bring forth, in a similar fashion, sexist behaviors.

Johnson (2005) argues that most discussions of gender-based violence focus on individuals, rather than patriarchy as a social system. Instead of asking questions such as "what type of men commit emotional and controlling abuse," his perspective indicates that we should examine aspects of the patriarchal social system that encourage or facilitate the use of emotional and controlling abuse of women by men. In this way, Johnson compares patriarchal social systems to institutional racism, in that

"specific acts of violence directed against women because they are women are related to the social oppression of women as a group, just as specific acts of violence directed against blacks because they are black are related to the existence of racial oppression in society as a whole" (italics in original; 2005, p. 49).

We suggest that the relative status of a man-woman couple is a reflection or proxy measure of the patriarchal nature of the relationship. In relating relative status to the experience of abusive behaviors, Goode (1971) was first to suggest that status reversal couples and couples in which only the male works (and the female does not) experienced more physical abuse than relationships characterized by status parity. He argued that men who lack power, as measured by factors such as lower income, lower occupational status, or little education, may use violence to obtain power in the relationship. Men have traditionally possessed greater control in intimate relationships, which has been connected to their status as breadwinner (Tichenor 1999. 2005). Emotional abuse is perpetrated by both men and women in the context of relationships, however, and the increase of married women in the labor force has led to a change in the 
quality of intimate relationships (Nock 2001) and this change has been linked to the perpetration of violence towards women (Anderson 1997; Macmillan and Gartner 1999). This "backlash" against women, where men try to regain control by exerting violence against their partners, is associated with employment.

Relationships of equally dependent partners that embrace egalitarian decision making and an equal division of power within the family are found to report higher relationship satisfaction (Tichenor 1999; Schoen et al. 2002), and studies report that such couples experience low levels of conflict, aggression, emotional abuse, and physical harm (Nock 2001; Kaukinen 2004). However, if females break away from historically held gender roles (i.e., stay-at-home mother or working at a menial job), this might be viewed as a challenge to their partner's masculinity as provider or breadwinner, which may ultimately result in violence (Macmillan and Gartner 1999). Thus, higher levels of gender equality can lead to a backlash against women by men who are threatened by their partners' powerful roles.

The following categories capture the various status relationships examined in the literature on marital quality. Status parity signifies couples in which the partners have a similar occupational status in the workforce. Both partners are either employed or unemployed and have similar educational backgrounds. Traditional status couples are partners in which status incompatibility favors men. These relationships are characterized by men who have higher education than their partner and also are the primary "breadwinner" in the family. Men are traditionally employed while their wives or partners are not. Status reversal, the least common among intimate relationships, characterizes relationships in which the female is employed and her husband or partner is not. In these relationships, the female typically has a higher education and contributes more than her partner to the household income (Tichenor 2005).

Studies by Macmillan and Gartner (1999) and Kaukinen (2004) demonstrate the importance of examining the connection between economic contributions, power, and control and offer support of a backlash against women not in the traditional relationships. Examining a sample of Canadian women, these authors argue that a woman's risk for violence is conditioned by her employment and the employment of her partner. Women are at a greater risk of control and emotional abuse when their partner is not employed, as this challenges their self-view as breadwinner, and might encourage controlling behaviors and emotional abuse to reassert their authority at home (Kaukinen 2004). A female's educational attain- 
ment protects her from control and emotional abuse if her partner has a similar education; however, exceeding her partner's education attainment increases her likelihood of being victimized by emotional abuse and control. This pattern holds not only for education, but for income as well. For example, McCloskey (1996) and Kaukinen (2004) found that women whose economic resources approached or exceeded their partners' resources were more likely to report victimization. It appears that greater equality or parity between partners reduces conflict between partners unless it threatens a man's position of power, in which case it can actually increase victimization or backlash (Brewer and Smith 1995; Gauthier and Bankston 1997; Whaley and Messner 2002; Stark, 2007).

\section{Alcohol Abuse and Intimate Partner Violence}

A number of researchers have examined the correlation between alcohol abuse and intimate partner violence, as well as the relationship between alcohol-induced aggression and violent behavior in general (Parker and Auerhahn 1998). Research has clearly shown a statistically significant relationship between alcohol abuse and violence between partners (Miller et al. 1989; O'Farrell et al. 1999; Testa et al. 2003; Thompson and Kingree 2006). For example, conducting a meta-analysis of quantitative studies of men who batter their partners, Tolman and Bennett (1990) found that alcohol use ranged from 56 percent to 70 percent of these offenders. The authors concluded that chronic alcohol abuse is a predictor of physical abuse. In addition, Leonard and Quigley (1999) examined a sample of newlyweds and reported that drinking by husbands was common in severely violent encounters. Similarly, analyzing data from the National Violence against Women Survey, Thompson and Kingree (2006) found that women whose partners had been drinking were more likely to report an injury than women whose partners were not drinking.

However, whether alcohol causes intimate partner violence is still debated. Some argue that alcohol abuse does not cause intimate partner violence because alcohol is not involved in all cases of domestic violence and men who do drink do not always abuse their partners. For example, Barnett and Fagan (1993) found evidence that the abuser and his victim are more likely to drink after the violent episode than before it. Moreover, it is generally accepted that the aggression-enhancing effects of alcohol occur in conjunction with other factors such as life stress, depression, and anger (Barnett and Fagan 1993; Neff et al. 1995). The role of alcohol in domestic violence is complex, but we argue that it is important to examine both the offender's 
and victim's alcohol consumption, as research indicates that a victim's alcohol use is often associated with a partner's alcohol use (Leadley et al. 2000).

A few studies have examined the impact of the victim's use of alcohol. For example, two studies indicate that alcohol consumption has little impact on being the victim of violence (Cogan and Ballinger 2006; Thompson and Kingree 2006). These studies indicate that alcohol use by a woman's partner increases her chance of victimization, but her own alcohol use does not contribute to her victimization. However, a more recent study using heavy-drinking college students reported that emotional and physical abuse was likely when both the victim and perpetrator were under the influence of alcohol (Roudsari et al. 2009). It is important, therefore, to further test this finding using a sample of the general population with exact measures of their alcohol consumption. In this study, we take a complex look at the use of alcohol by partners in a relationship by examining both main effects and interaction effects of alcohol use by each partner and its impact on emotional abuse by the male partner.

\section{The Current Study and Research Hypotheses}

We developed eight research hypotheses based on combined impact of economics, challenges to men's masculinity, and alcohol consumption on emotional abuse as outlined by the literature review above. From a socioeconomic standpoint, the first four hypotheses suggest that economic hardship and a lack of resources are associated with higher rates of emotional abuse. The next two hypotheses are guided by the notion that relationships that challenge a male's masculinity as primary provider or breadwinner for his family will result in a greater reliance on emotional abuse to exert power and control (although Hypothesis 5 is also consistently with arguments based on economics). The final two hypotheses focus on the manner in which alcohol use by the respondent and/or her partner can increase emotional abuse in a relationship.

H1: Education will be negatively related to emotional abuse.

H2: Poverty status will be positively related to emotional abuse.

H3: Women in relationships in which neither the male nor the female is employed will experience more emotional abuse than women in relationships where both are employed.

H4: Women in traditional status relationships (male employed, female not) will experience less emotional abuse than women in relationships in which both partners are unemployed. 
H5: Women in a status reversal relationship (male not employed, female employed) will experience more emotional abuse than women in relationships where both are employed.

H6: Women in a traditional status relationship (male employed, female not) will experience less emotional abuse than those in relationships where both are employed.

H7: The frequency of partner's alcohol consumption and the average amount consumed will be positively related to emotional abuse.

H8: As respondent's alcohol use increases, the effect of partner's alcohol use on emotional abuse will increase.

\section{METHODS}

\section{Data}

Data are from the survey of Violence and Threats of Violence Against Women and Men in the United States, 1994 through 1996. Conducted in 1994 and ending in 1996, the survey relied on telephone interviews with a national probability sample of approximately 8,000 English-speaking women and 8,000 men ages 18 and older residing in households throughout the United States. Respondents were asked about their general fear of violence and ways in which they managed those fears, emotional abuse on the part of intimate partners, and incidents of actual or threatened violence experienced by all types of offenders. A Spanish language version of the survey was used for respondents who spoke Spanish. Those disclosing victimization were asked more detailed questions about the characteristics and consequences of those experiences. The participation rate among female sample was 72 percent. Of those eligible women who started the interviews, 97 percent completed the survey (see Tjaden and Thoennes 2000). Because the focus of this study is on the victimization of women and the characteristics of their intimate partners who use nonphysical abuse, we employ only the female sample for the analysis below. This research does not negate the existence of emotional abuse by wives or girlfriends, but since the frequency and severity are much more likely towards females than males, it will test emotional abuse toward females. We focus on respondents and partners between the ages of 18 through 64 as these are the ages in which respondents are more likely to be in the labor force $(N=4,838)$. 


\section{Dependent Variable}

The dependent variable indicates whether the respondent experiences controlling and emotional abuse. To determine power and controlling behavior, female respondents were asked if their current husband/ boyfriend is either a jealous or possessive person; tried to provoke arguments; tried to limit their contact with family or friends; and insists on knowing who they are with at all times. To determine emotional abuse, female respondents were asked if their current partners called them names or put them down in front of others; made them feel inadequate; shouts or swears at them; and if their partner frightens them. These questions were then summed to create an emotional abuse scale. A scale reliability analysis of these questions demonstrated an alpha of .79. An exploratory analysis revealed that the dependent variable was heavily skewed, thus violating the assumption of normality. This is largely due to the relatively rare nature of these acts.

\section{Independent and Control Variables}

The independent variables of greatest interest in this study are those reflecting alcohol use and abuse of the partner and the respondent and dummy variables reflecting status compatibility of the relationship, as measured by whether or not the respondent and/or their partner are in the workforce. Status compatibility is captured by the respondent's and her partner's employment status. In this research, the respondent is considered employed if they indicated they were employed full-time, parttime, or are in the military and not employed if at the time of the survey indicated they were unemployed but looking for work or a homemaker. The respondent's husband/partner is considered employed if they were employed full-time, part-time, or are in the military and not employed if at the time of the survey were unemployed but looking for work, or a homemaker. Status Compatibility is captured then by four dummy variables. Traditional status is coded 1 for female respondents who were not working, but their male partners are and 0 otherwise. Status Parity is coded 1 if both partners are working and 0 otherwise. Status Reversal is coded 1 if only female respondents are working and their male partners are not and 0 otherwise. Both Unemployed status is coded 1 if both respondent and her partner are not working. Although information on whether or not women want to work would be important because as staying at home and not working might be a demand of the male partner, this infor- 
mation is not available in the current dataset, and cannot be included in the analysis.

Information on alcohol consumption by both respondents and their partners reflects both the frequency of alcohol consumption and, for those who reported drinking, the average amount of alcohol drank on these occasions. Specifically, respondents were asked: "During the past 12 months, how often did you usually drink any alcoholic beverages including beer, light beer, wine coolers, or liquor?" The same question was asked regarding their partner's alcohol consumption. Frequency is assessed by asking how often respondents and their partners drank any alcoholic beverage during the last twelve months. Specifically, they were asked to indicate (1) every day, (2) nearly every day, (3) three or four days a week, (4) one or two days a week, (5) two or three days a month, (6) once or twice a month, or (7) never. The variable is reverse coded in the current analysis and is coded from (1) never to (7) everyday. Those individuals who reported alcohol use by themselves or their partners were then asked the average number of drinks consumed per occasion, 1 through 19, with 20 or more drinks coded as 20 . Those respondents who did not drink scored the value of 0 .

The survey contains information on the following demographic characteristics of the respondents and will be serving as control variables. Married is a dummy variable reflecting whether the respondent and partner are legally married. Age of the respondents is coded in years. Two measures of socioeconomic status are included in the analysis: education and a proxy for poverty status. Education is coded from (1) no schooling to (7) post-graduate. Coverage of medical care will be a proxy variable for poverty, due to missing data for the personal income variable. Poverty is coded 1 for respondents whose medical care is covered by Medicaid or MediCal, by a free or low income clinic, or uninsured and zero otherwise. Race is captured by four dummy variables: White, Black, Hispanic, and other minority, which includes American Indian or Alaskan Native, Asian or Pacific Islander, or mixed raced.

In addition to these demographic variables, the Conflict Tactics Scale is adopted to capture physical victimization experienced as a child. Respondents were asked a series of 12 questions; however, a scale reliability analysis indicated that nine particular questions offered that highest alpha of .812. These nine questions - throw something at you that could hurt you; push, grab, or shove you; pull your hair; slap or hit you; kick or bite you; choke or attempt to drown you; hit you with some object; beat you up; threaten you with a knife or other weapon besides a gun; and use 
a knife or other weapon on you besides a gun - were summed to create a scale to measure child victimization. In this research, we utilize childhood victimization in our models as a control for an overall propensity for victimization that might not be captured by our other independent variables. Just as researchers should control for early health status in studies of factors that influence adult health status or criminologists should control for early involvement in delinquency in models predicting later delinquency, we argue that this variable serves as at least a partial statistical control for women whose emotional vulnerability might lead them towards controlling and abusive males.

\section{Multivariate Analytical Techniques}

Most of the women in the sample did not experience emotional/controlling abuse and, consequently, have a zero value on the dependent variable. Of 4,413 women with full information for all variables in the multivariate models, 3,328 were not victims of abuse. The resulting variable is highly skewed, complicating analysis with OLS regression. Due to this large number of zero values in the dependent variable, it is statistically necessary to control for bias due to left censoring (Breen 1996; Long 1997). Consequently, maximum likelihood tobit regression is used instead of OLS regression in order to produce unbiased and efficient estimates in the presence of censored data. Tobit models assume that the manifest dependent variable is an imperfect reflection of the true, unmeasured (or latent) variable.

As a methodological check on our tobit models, we transformed the dependent variable to reduce skewness by adding one to the existing value and logging it. OLS regression was then applied to this transformed variable. The sign and level of significance of all estimated regression coefficients were consistent with our tobit models. In addition, we tested for multicollinearity amongst the independent variables by calculating the variance inflation factors (VIF). These values ranged from 1.015 to 1.545, indicating that multicollinearity is not a problem. These results are available from the authors upon request.

\section{RESULTS}

Table 1 reports the descriptive statistics for all variables. After omitting respondents with missing data and restricting the sample between the ages of 18 and 64 (those women most likely to be in the workforce), a total of 4,838 women respondents were used in the final analysis. Regard- 
Table 1. Descriptive statistics for variables used in the analysis

\begin{tabular}{|c|c|c|c|c|}
\hline Variables max & Mean & $S D$ & Min & $n$ \\
\hline \multicolumn{5}{|l|}{ Dependent variable } \\
\hline Emotional Abuse & 0.52 & 1.21 & 0 & 9 \\
\hline \multicolumn{5}{|l|}{ Demographics } \\
\hline Age & 40.38 & 11.07 & 18 & 64 \\
\hline White & 0.81 & & 0 & 1 \\
\hline Hispanic & 0.08 & & 0 & 1 \\
\hline Black & 0.06 & & 0 & 1 \\
\hline Other Race & 0.04 & & 0 & 1 \\
\hline Poverty & 0.07 & & 0 & 1 \\
\hline Education & 4.84 & 1.13 & 1 & 7 \\
\hline Married & 0.89 & & 0 & 1 \\
\hline \multicolumn{5}{|l|}{ Status compatibility } \\
\hline Traditional Status & 0.24 & & 0 & 1 \\
\hline Both Employed & 0.60 & & 0 & 1 \\
\hline Status Reversal & 0.08 & & 0 & 1 \\
\hline Both Unemployed & 0.08 & & 0 & 1 \\
\hline Child Victimization & 1.00 & 1.68 & 0 & 10 \\
\hline \multicolumn{5}{|l|}{ Alcohol Prevalence } \\
\hline Respondent & 2.19 & 1.36 & 1 & 7 \\
\hline Partner & 2.80 & 1.77 & 1 & 7 \\
\hline \multicolumn{5}{|l|}{ Alcohol Amount } \\
\hline Respondent & 0.70 & 1.32 & 0 & 20 \\
\hline Partner & 1.19 & 1.98 & 0 & 20 \\
\hline
\end{tabular}

ing the dependent variable, the mean for the dependent variable reflecting the number of types of emotional/controlling abuse experienced by the women is 0.52 . Nearly 90 percent of the respondents were married at the time of the survey and 24.2 percent indicated they were currently in a traditional status relationship. Examining the other employment scenarios, 60 percent and 8 percent of respondents indicated they were in a status parity and status reversal relationship, respectively. Finally, 8 percent of couples in this survey were both unemployed. Regarding race/ethnicity, 81 percent of respondents are white, 8 percent are Hispanic, 6 percent are black or African American, and 4 percent of respondents were classified as "other race." Average education for the current sample is high school and the average age is about 40 years. Respondents indicated that their partners surpassed them in both frequency and amount of reported alcohol consumption.

Table 2 reports the bivariate correlations among variables used in the analysis. Only one racial category is included in these correlations (white versus non-white) in order to simplify the table. Emotional and control- 


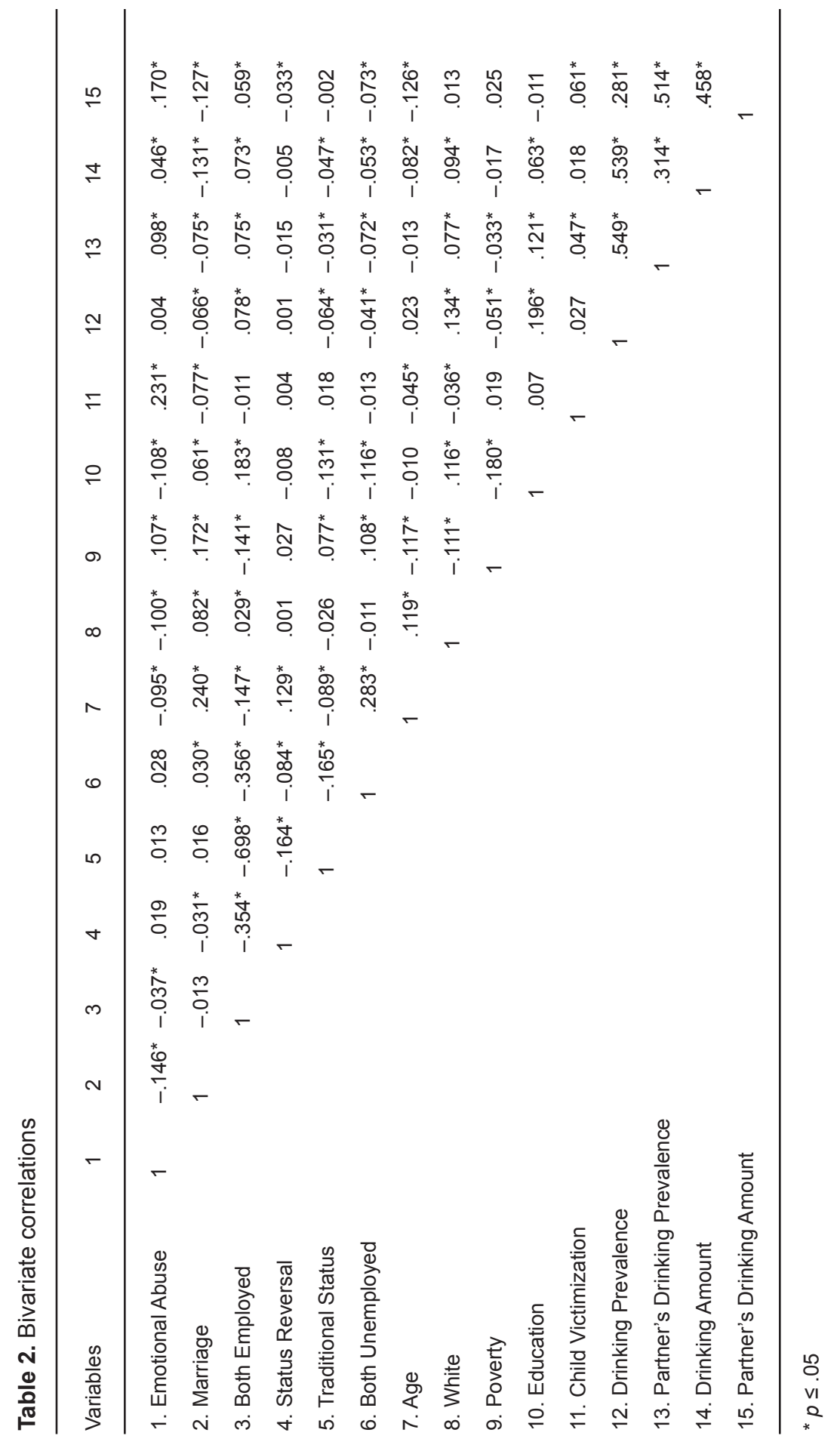


ling abuse is positively related to poverty, childhood victimization, and three of the four alcohol consumption variables. In contrast, emotional and controlling abuse is negatively related to marriage, age, white racial status, education, and both partners being employed.

\section{Economic Hypotheses}

Table 3 provides the results of two logistic regression models focusing on the impact of respondent and partner employment on emotional abuse. In order to examine our hypotheses, it was necessary to omit a different employment variable as the reference category in each model. Otherwise, Model 1 and Model 2 are identical. Consistent with the first hypothesis, women's level of education is negatively related to emotional abuse. Also, poverty is positively related to emotional abuse, supporting Hypothesis 2. The third hypothesis suggests that emotional abuse will be

Table 3. Tobit models predicting emotional abuse

\begin{tabular}{|c|c|c|c|c|}
\hline \multirow[b]{2}{*}{ Variable } & \multicolumn{2}{|c|}{ Model 1} & \multicolumn{2}{|c|}{ Model 2} \\
\hline & b & $S E$ & b & $S E$ \\
\hline Married & $0.794^{*}$ & 195 & $-0.794^{*}$ & .195 \\
\hline Age & $-0.025^{*}$ & .006 & $-0.025^{*}$ & .006 \\
\hline Hispanic & $0.647^{*}$ & .223 & $0.647^{*}$ & .223 \\
\hline Black & $1.252^{*}$ & .248 & $1.252^{*}$ & .248 \\
\hline Other Race & $1.043^{*}$ & .302 & $1.043^{*}$ & .302 \\
\hline Education & $-0.318^{*}$ & .060 & $-0.318^{*}$ & .060 \\
\hline Poverty & $0.704^{*}$ & .241 & $0.704^{*}$ & .241 \\
\hline Child Victimization & $0.444^{*}$ & .003 & $0.443^{*}$ & .003 \\
\hline Drinking & -0.124 & .064 & -0.124 & .064 \\
\hline Partner's Drinking & $0.150^{*}$ & .046 & $0.150^{*}$ & .046 \\
\hline No. of Drinks & 0.028 & .056 & 0.028 & .056 \\
\hline No. of Partner's Drinks & $0.183^{*}$ & .035 & $0.183^{*}$ & .035 \\
\hline \multicolumn{5}{|l|}{ Employment variables } \\
\hline Status Reversal & $0.483^{*}$ & .240 & -0.105 & .316 \\
\hline Traditional Status & -0.110 & .154 & $-0.698^{*}$ & .266 \\
\hline Both Unemployed & $0.588^{*}$ & .250 & \multicolumn{2}{|c|}{ omitted category } \\
\hline \multirow[t]{5}{*}{ Both Employed } & & gory & $-0.588^{*}$ & .250 \\
\hline & \multicolumn{4}{|c|}{-Log likelihood = 4,084.53 } \\
\hline & \multicolumn{4}{|c|}{ Model $X^{2}=455.5, p=.000$} \\
\hline & & \multicolumn{3}{|c|}{ Left-censored = 3328} \\
\hline & & \multicolumn{3}{|c|}{ Uncensored $=1085$} \\
\hline
\end{tabular}

Model 1, reference category for the employment variables is "both employed." Model 2, reference category for the employment variables is "both unemployed."

${ }^{*} p \leq .05$ 
more prevalent in relationships where both individuals are unemployed, as compared to relationships where both individuals are employed. The significant tobit regression coefficient $(b=.588, p<.05)$ for Both Unemployed in the first model indicates that this hypothesis is also supported. Model 2 allows an examination of Hypothesis 4, which states that women in traditional relationships will experience less abuse than women in relationships where both partners are unemployed. This hypothesis, too, is supported $(\mathrm{b}=-.698, p<.05)$.

\section{Challenges to Masculinity}

Hypothesis 5 states that relationships in which only the female partner is employed (status reversal) should involve more emotional abuse than dual-earner relationships. This hypothesis is based not only on issues of economic security but also on the possibility that challenges to masculinity also precipitate emotional abuse. The first model supports this hypothesis $(b=.483, p<.05)$. The sixth hypothesis indicates that women in relationships in which only the male partner is employed should experience less emotional abuse than in a dual-earner relationship. The nonsignificant tobit regression coefficient $(b=-.110)$ for Traditional Status in the first model indicates that the sixth hypothesis is not supported.

\section{Alcohol Use}

The models in Table 3 indicate that both the prevalence of the male partner's drinking $(b=.150, p<.05)$ and the average number of drinks consumed during these episodes of drinking $(b=.183, p<.05)$ are positively related to emotional abuse, supporting Hypothesis 7. The models presented in Table 4 explore these relationships further by examining interaction effects created from the alcohol prevalence variables and the variables representing the average number of drinks per episode. Hypothesis 8 states that the effect of the male partner's alcohol use on emotional abuse will be exacerbated if the female respondent also drinks. Interaction effects representing the prevalence of drinking (Model 1) and the number of drinks per episode (Model 2) do not support this contention. We created additional interactions to examine the possibility that the effect of the prevalence of alcohol use on emotional abuse is exacerbated as the average number of drinks increases. This does not appear to be the case for the female respondents (Model 3) but this interaction is positive and significant for the male partners $(b=.05, p<.05)$ in Model 4. 
Table 4. Tobit models with alcohol interactions

\begin{tabular}{|c|c|c|c|c|c|c|c|c|}
\hline \multirow[b]{2}{*}{ Variable } & \multicolumn{2}{|c|}{ Model 1} & \multicolumn{2}{|c|}{ Model 2} & \multicolumn{2}{|c|}{ Model 3} & \multicolumn{2}{|c|}{ Model 4} \\
\hline & $\mathrm{b}$ & $S E$ & $b$ & $S E$ & $\mathrm{~b}$ & $S E$ & $\mathrm{~b}$ & $S E$ \\
\hline Married & _0.79* & .20 & $-0.79^{*}$ & .19 & $-0.79^{*}$ & .19 & $-0.76^{*}$ & .19 \\
\hline Age & $-0.02^{*}$ & .01 & $-0.02^{*}$ & .01 & $-0.02^{*}$ & .01 & -0.03 & .01 \\
\hline Hispanic & $0.65^{*}$ & .22 & $0.65^{*}$ & .22 & $0.65^{*}$ & .22 & $0.66^{*}$ & .22 \\
\hline Black & $1.25^{\star}$ & .25 & $1.25^{*}$ & .25 & $1.26^{*}$ & .25 & $1.18^{*}$ & .25 \\
\hline Other Race & $1.05^{*}$ & .30 & $1.04^{*}$ & .30 & $1.05^{*}$ & .30 & $1.05^{*}$ & .30 \\
\hline Education & $-0.32^{*}$ & .06 & $-0.32^{*}$ & .06 & $-0.32^{*}$ & .06 & $-0.31^{*}$ & .06 \\
\hline Poverty & $0.71^{*}$ & .24 & $0.70^{*}$ & .24 & $0.72^{*}$ & .24 & $0.68^{*}$ & .24 \\
\hline Child Victimization & $0.44^{*}$ & .03 & $-0.44^{*}$ & .03 & $0.44^{*}$ & .03 & $0.44^{*}$ & .03 \\
\hline Status Reversal & $0.47^{*}$ & .24 & $0.48^{*}$ & .24 & $0.48^{*}$ & .24 & $0.48^{*}$ & .24 \\
\hline Traditional Status & -0.10 & .15 & -0.11 & .15 & -0.11 & .15 & -0.12 & .15 \\
\hline Both Unemployed & $0.60^{*}$ & .25 & $0.59^{*}$ & .25 & $0.59^{*}$ & .25 & $0.58^{*}$ & .25 \\
\hline Drinking & 0.03 & .12 & $-0.13^{*}$ & .06 & -0.09 & .07 & -0.12 & .06 \\
\hline Partner's Drinking & $0.23^{*}$ & .07 & $0.15^{*}$ & .05 & $0.15^{*}$ & .05 & 0.09 & .05 \\
\hline No. of Drinks & 0.02 & .06 & 0.05 & .07 & 0.15 & .14 & 0.05 & .06 \\
\hline No. of Partner's Drinks & $0.18^{*}$ & .034 & $0.19^{*}$ & .04 & $0.18^{*}$ & .03 & -0.04 & .09 \\
\hline Drinking $\times$ Partner's Drink & -0.04 & .03 & & & & & & \\
\hline $\begin{array}{l}\text { No. of Drinks } \times \\
\text { Partner's No. of Drinks }\end{array}$ & & & -0.00 & .01 & & & & \\
\hline Drinking $\times$ No. of Drinks & & & & & -0.04 & .04 & & \\
\hline $\begin{array}{l}\text { Partner's Drinking } \times \\
\text { Partner's No. of Drinks }\end{array}$ & & & & & & & $0.05^{*}$ & .02 \\
\hline -Log likelihood & \multicolumn{2}{|c|}{$4,083.40$} & \multicolumn{2}{|c|}{$4,084.39$} & \multicolumn{2}{|c|}{$4,084.11$} & \multicolumn{2}{|c|}{$4,080.434$} \\
\hline Model $x^{2}=$ & \multicolumn{2}{|c|}{$\begin{array}{l}457.81 \\
p=.000\end{array}$} & \multicolumn{2}{|c|}{$\begin{array}{l}455.83 \\
p=.000\end{array}$} & \multicolumn{2}{|c|}{$\begin{array}{l}456.58 \\
p=.000\end{array}$} & \multicolumn{2}{|c|}{$\begin{array}{l}463.75 \\
p=.000\end{array}$} \\
\hline
\end{tabular}

Left-censored observations $=3,328$; uncensored observations $=1,085$.

${ }^{*} p \leq .05$

\section{DISCUSSION AND CONCLUSION}

The primary goal of this research is to examine nonphysical abuse in intimate partner violence. Research on intimate partner violence and the link between relationship compatibility and abuse have been largely conducted with a focus on poverty, welfare, or homelessness (Kwesiga et al. 2007) - with little variability in employment, education, and social status. This study is one of only a handful of studies that examines emotional abuse in the context of a person's relationship compatibility, and the validity of our results is enhanced by the inclusion of measures of alcohol use by both partners.

A central focus in the literature on domestic violence is the correlation between women's social and economic status and experiencing violence. 
At the core of this argument is the idea that women who have more resources are less dependent on men and, subsequently, less vulnerable to abuse. Examining this assertion, we found that education was negatively related to emotional abuse and that poverty was positively related to abuse, providing support for our first two hypotheses. Representing lower rungs of the social and economic ladder, women exhibiting these characteristics may be exposed to greater levels of gender inequality which may elevate their physical and nonphysical victimization rate by placing them at a disadvantage relative to men. This research is consistent with the notion that educational achievements and alleviating poverty should serve to buffer women from emotional abuse.

The third and fourth hypotheses state that economic security in the form of employment should also reduce the emotional abuse of women. Consistent with this notion, we find that abuse is more common is when both partners are employed, versus when neither partner is employed. Similarly, we find that if the man is employed, this results in less abuse than if neither partner is employed.

The next two hypotheses, however, are based on the assumption that the employment of women and their partners is an issue that is more complex than a simple reflection of financial security. Physical and nonphysical abuse is not the exclusive action of men whose female partners lack socioeconomic resources. Males who hold strong masculine gender norms, such as being the primary provider for their families, may be more likely to use violence if they feel that these norms are being violated (see Heckert et al. 1998). Thus, males who hold a worldview in which the man should be primary provider may perceive a successful, financially independent partner as a threat to this worldview. Emotional abuse might be one response to that threat.

Little support is found for this argument. Hypothesis 5 is predicted by arguments based on both economic dependency and gender-role theory, but is contrary to a pure "economic security" argument. Our research supports this hypothesis, in that women in relationships in which only the woman is employed, and the husband is not, experience more emotional abuse than women in relationships in which both partners are employed. Presumably, the economic strain produced by an unemployed male partner, combined with the challenge to masculinity experienced by a man who is being supported by his female partner, results in emotional and controlling abuse that is directed at the woman.

Hypothesis 6 was based on gender-role considerations alone and, while the regression coefficient is in the predicted direction, it is not significant 
and this hypothesis is not supported. Consequently, the one hypothesis that is based solely on arguments reflecting "challenges to masculinity" as a cause for emotional abuse does not receive report in our research. Overall, then, economic considerations appear to be the primary motivation for male emotional abuse directed towards females in the context of intimate relationships.

Although portions of the results are not consistent with findings of previous research examining challenges to gender roles and subsequent abuse (i.e., Macmillan and Gartner 1999; Kaukinen 2004), the conclusions may support alternative explanations. For example, Nock (2001) argues that boys and young men are now more likely to be raised by single, working mothers (also see Aulette 2002). As more and more young males grow up in these nontraditional households, they are more likely to believe in nontraditional gender roles (Nock 2001). If being a working mother has become more culturally acceptable, males who marry females with higher education, income, and social status may not be threatened by such a relationship and the likelihood of using violence or emotional abuse to secure masculinity is reduced. Similarly, the public's attitudes about gender roles have changed. For example, Cassidy and Warren (1997) found that women who were full-time employed were more likely to support nontraditional gender roles as compared to stay-at-home mothers who were more likely to hold onto traditional gender roles. Currently, more marriages are formed in which the female is already participating in the labor force (Nock 2001) and research indicates that females in these relationships are contributing more of the income and making more marital decisions than females did in the past (Rogers and Amato 2000). Traditional relationships in which the male works and the female does not are being replaced by dual income earning couples. As women continue to increase their representation in the workforce obtaining higher wages and higher occupational status, more relationships will approximate status parity (see Nock 2001). Also, current economic downturns should provide an interesting context for continued research on the role of economics and gender roles on intimate partner abuse.

The findings regarding alcohol are straightforward. Drinking by the female respondents does not lead to victimization from emotional abuse, nor does drinking by the females interact with the effect of drinking by their male partners. However, both the prevalence of drinking by the male partner and the number of drinks per episode increases the likelihood of emotional and controlling abuse. Moreover, the one significant interaction effect indicates that drinking by the male partner is more likely 
to produce abuse when the average number of drinks is higher. The policy implications of these findings are that, in addition to possible physical violence, emotionally and controlling abuse are potentially additional negative outcomes from alcohol use and abuse by male partners. Future research should not neglect to control for substance abuse, particularly that of male partners.

A number of shortcomings of this research should be discussed. First, when using self-report measures of any human involvement, full disclosure can be a problem (Fowler 2002). Because this survey relied on selfreported victimization, some respondents may not be willing to disclose full victimization to avoid embarrassment and/or to avoid acknowledging abusive behaviors by their partners. Furthermore, because the survey was conducted over the telephone, there is the possibility of the victimizer overhearing the administration of the survey, thus possibly reducing the likelihood of fully disclosing victimization. Second, the data is retrospective and recollection of events can be a problem in self-reported surveys (Fowler 1995). Third, as discussed out by Brecklin and Ullman (2002), data on alcohol intake in this survey is limited by a lack of information on type or amount of alcohol (how small or large is one drink?) consumed by the respondents. Fourth, when measuring alcohol intake, the survey relied on the victim's report about their partner's alcohol consumption. Although these secondhand reports are potentially problematic, research indicates that victims of intimate partner violence can accurately report their partner's alcohol use (Lindquist et al. 1997). Finally, some readers may reject our measure of gender ideologies as employment status being a proxy for traditional gender attitudes. Our research remains consistent, however, with similar studies making the same assumption (MacMillan and Gartner 1999; Kaukinen 2004).

Despite these limitations, this study contributes to the much needed body of research on nonphysical violence between intimates. We suggest four routes for future research. First, if we are to more completely understand violence against women, we must pay more attention to controlling behaviors in relationships (Outlaw 2009). Future surveys should include questions concerning control tactics, in addition to actual physical violence, perpetrated by both partners. Only then can scholars make distinctions between the use of control and violence by each sex. Moreover, additional data and research are needed to examine new conceptualizations of the interplay between coercion, control, and intimate partner violence, such as that proposed by Dutton and Goodman (2005). Second, to understand violence between couples, surveys need to address the issue of gen- 
der symmetry and asymmetry. Research is needed that includes measures of defensive violence by those who are assaulted, attacked, or emotionally abused. Much of the domestic violence literature is founded on data that does not allow a determination of whether a violent act against one's partner was an act of self-defense or an act of aggression. Third, data and research on partner violence among same-sex couples promises to increase our knowledge of the roles of relationship power and symmetry and domestic violence. Finally, measures of substance use should be expanded to include illicit substances, and measures of abuse, in addition to use.

\section{REFERENCES}

Anderson, Kristin L. 1997. "Gender, Status, and Domestic Violence: An Integration of Feminist and Family Violence Approaches." Journal of Marriage and Family 59:655-669.

Aulette, Judy Root. 2002. Changing American Families. Boston: Allyn \& Bacon.

Barnett, Ola W. and Ronald W. Fagan. 1993. "Alcohol Use in Male Spouse Abusers and their Female Partners." Journal of Family Violence 8:1-25.

Brecklin, Leanne R. and Sarah E. Ullman. 2002. "The Roles of Victim and Offender Alcohol Use in Sexual Assaults: Results from the National Violence Against Women Survey." Journal of Studies on Alcohol 63:57-63.

Breen, Richard. 1996. Regression Models: Censored, Sample Selected, or Truncated Data. Thousand Oaks, CA: Sage.

Brewer, Victoria E. and M. Dwayne Smith. 1995. "Gender Inequality and Rates of Female Homicide Victimization Across U.S. Cities." Journal of Research in Crime and Delinquency 32:175-190.

Carbone-López, Kristin, Candace Kruttschnitt, and Ross Macmillan. 2006. “Patterns of Intimate Partner Violence and their Associations with Physical Health Psychological Distress, and Substance Use." Public Health Reports 121:382-392.

Cassidy, Margret L. and Bruce O. Warren. 1997. "Family Employment Status and Gender Role Attitudes: A Comparison of Women and Men College Graduates." Gender $\mathcal{E}$ Society 10:312-329.

Cogan, Rosemary and Bud C. Ballinger. 2006. "Alcohol Problems and the Differentiation of Partner, Stranger, and General Violence." Journal of Interpersonal Violence 21:924-935.

Cunradi, Carol B., Raul Caetano, and John Schafer. 2002. "Socioeconomic Predictors of Intimate Partner Violence Among White, Black, and Hispanic Couples in the United States." Journal of Family Violence 17:377-389.

DeKeseredy, Walter S. 1995. “Enhancing the Quality of Survey Data on Women Abuse: Examples from a National Canadian Study." Violence Against Women 1:158-173.

DeKeseredy, Walter S. 2000. "Current Controversies on Defining Nonlethal Violence Against Women in Intimate Heterosexual Relationships." Violence Against Women 6:728-746. 
Demaris, Alfred and Catherine Kaukinen. 2005. “Violent Victimization and Women's Mental and Physical Health: Evidence from a National Sample." Journal of Research in Crime and Delinquency 42:384-411.

Dobash, R. Emerson and Russell P. Dobash. 1979. Violence Against Women. New York: The Free Press.

Dutton, Mary Ann and Lisa A. Goodman. 2005. "Coercion in Intimate Partner Violence: Toward a New Conceptualization." Sex Roles 52:743-756.

Felson, Richard B. and Steven F. Messner. 2000. "The Control Motive in Intimate Partner Violence." Social Psychology Quarterly 63:86-94.

Fowler, Floyd J. Jr. 1995. Improving Survey Questions: Design and Evaluation. Thousand Oaks, CA: Sage.

Fowler, Floyd J. Jr. 2002. Survey Research Methods, 3rd edition. Thousand Oaks, CA: Sage.

Frias, Sonia M. and Ronald J. Angel. 2005. "The Risk of Partner Violence Among LowIncome Hispanic Subgroups." Journal of Marriage and Family 67:552-564.

Gauthier, DeAnn K. and William B. Bankston. 1997. "Gender Equality and the Sex Ratio of Intimate Killing." Criminology 35:577-600.

Goode, William J. 1971. "Force and Violence in the Family." Journal of Marriage and Family 33:624-636.

Greenfeld, Lawrence A., Michael R. Rand, Diane Craven, Patsy A. Klaus, Craig A. Perkins, Cheryl Ringel, Greg Warchol, Cathy Maston, and James Alan Fox. 1998. Violence by Intimates: Analysis of Data on Crimes by Current or Former Spouses, Boyfriends, and Girlfriends. Washington, DC: U.S. Department of Justice, Bureau of Justice Statistics.

Hamby, Sherry L. and David B. Sugarman. 1999. "Acts of Psychological Aggression Against a Partner and their Relation to Physical Assault and Gender." Journal of Marriage and Family 61:959-970.

Heckert, D. Alex, Thomas C. Nowak, and Kay A Snyder. 1998. “The Impact of Husbands' and Wives' Relative Earnings on Marital Disruption." Journal of Marriage and Family 60:690-703.

Johnson, Allan G. 2005. The Gender Knot: Unraveling Our Patriarchal Legacy, rev. edition. Philadelphia: Temple University Press.

Johnson, Michael P. 2006. "Conflict and Control: Gender Symmetry and Asymmetry in Domestic Violence." Violence Against Women 12:1003-1018.

Kaukinen, Catherine. 2004. "Status Compatibility, Physical Violence, and Emotional Abuse in Intimate Relationships." Journal of Marriage and Family 66:452-471.

Kwesiga, Eileen, Myrtle P. Bell, Marshall Pattie, and Angela M. Moe. 2007. “Exploring the Literature on Relationships Between Gender Roles, Intimate Partner Violence, Occupational Status, and Organizational Benefits." Journal of Interpersonal Violence 22:312-326.

Leadley, Katrin, Catherine L. Clark, and Raul Caetano. 2000. “Couples' Drinking Patterns, Intimate Partner Violence, and Alcohol-Related Partnership Problems." Journal of Substance Abuse 11:253-263.

Leonard, Kenneth E. and Brian M. Quigley. 1999. “Drinking and Marital Aggression in Newlyweds: An Event-Based Analysis of Drinking and the Occurrence of Husband Martial Aggression." Journal of Studies on Alcohol 60:537-545. 
Leone, Janel M., Michael P. Johnson, Catherine L. Cohan, and Susan E. Lloyd. 2004. "Consequences of Male Partner Violence for Low-Income Minority Women." Journal of Marriage and Family 66:472-490.

Lindquist, Carol U., Lillian E. Sass, Denise Bottomley, Suzanne M. Katin, Jennifer D. Maddox, Rose M. Ordonez, and Craig N. Teofilo. 1997. "Should Abused Women's Reports of Partner Substance Abuse be Accepted as Valid?" Journal of Family Violence 12:75-83.

Long, J. Scott. 1997. Regression Models for Categorical and Limited Dependent Variables. Thousand Oaks, CA: Sage.

Loring, Marti Tamm. 1998. Emotional Abuse: The Trauma and Treatment. San Francisco: Jossey-Bass.

Macmillan, Ross and Rosemary Gartner. 1999. "When She Brings Home the Bacon: Labor-Force Participation and the Risk of Spousal Violence Against Women." Journal of Marriage and Family 61:947-958.

Margolin, Gayla, Richard S. John, and Louise Foo. 1998. "Interactive and Unique Rick Factors for Husbands' Emotional and Physical Abuse of Their Wives." Journal of Family Violence 13:315-344.

McCloskey, Laura Ann. 1996. "Socioeconomic and Coercive Power Within the Family." Gender \& Society 10:449-463.

Miller, Brenda A., William R. Downs, and Dawn M. Gondoli. 1989. “Spousal Violence Among Alcoholic Women as Compared to a Random Household Sample of Women." Journal of Studies on Alcohol 50:533-540.

Neff, James Alan, Bruce Holamon, and Tracy Davis Schluter. 1995. “Spousal Violence Among Anglos, Blacks, and Mexican Americans: The Role of Demographic Variables, Psychological Predictors, and Alcohol Consumption." Journal of Family Violence 10:1-21.

Nock, Steven L. 2001. “The Marriage of Equally Dependent Spouses." Journal of Family Issues 22:727-754.

O'Farrell, Timothy J., Valerie Van Hutton, and Christopher M. Murphy. 1999. "Domestic Violence Before and After Alcoholism Treatment: A Two-Year Longitude Study." Journal of Studies on Alcohol 60:317-321.

Outlaw, Maureen. 2009. "No One Type of Intimate Partner Abuse: Exploring Physical and Non-physical Abuse Among Intimate Partners." Journal of Family Violence 24:263-272.

Parker, Robert Nash and Kathleen Auerhahn. 1998. "Alcohol, Drugs, and Violence." Annual Review of Sociology 24:291-311.

Peterson, Ruth and William C. Bailey. 1992. "Rape and Dimensions of Gender Socioeconomic Inequality in U.S. Metropolitan Areas." Journal of Research in Crime and Delinquency 29:162-177.

Rennison, Callie Marie. 1999. Criminal Victimization 1998: Changes 1997-1998 with Trends 1993-1998. Washington, DC: U.S. Department of Justice, Bureau of Justice Statistics.

Rice, Christopher, Cynthia D. Mohr, Frances J. del Boca, Margaret E. Mattson, Leslie Young, Kathleen Brady, and Cynthia Nickless. 2001. "Self-Reports of Physical, Sexual, and Emotional Abuse in an Alcoholism Treatment Sample." Journal of Studies on Alcohol 62:114-123. 
Rogers, Stacy J. and Paul R. Amato. 2000. "Have Change in Gender Relations Affected Marital Quality?" Social Forces 79:731-748.

Roudsari, Bahman S., Mathew M. Leathy, and Scott T. Walters. 2009. "Correlated of Dating Violence Among Male and Female Heavy-Drinking College Students." Journal of Interpersonal Violence 24:1892-1905.

Salari, Sonia Miner and Bret M. Baldwin. 2002. "Verbal, Physical, and Injurious Aggression Among Intimate Couples Over Time." Journal of Family Issues 23:523-550.

Schoen, Robert, Nan Marie Astone, Kendra Rothert, Nicola J. Standish, and Young J. Kim. 2002. "Women's Employment, Marital Happiness, and Divorce." Social Forces 81:643-662.

Schwartz, Martin. 2005. "The Past and the Future of Violence Against Women." Journal of Interpersonal Violence 20:7-11.

Stark, Evan. 2007. Coercive Control: The Entrapment of Women in Personal Life. New York: Oxford University Press.

Stets, Jan E. 1995. "Modelling Control in Relationships." Journal of Marriage and Family 57:489-501.

Strauchler, Orin, Kathy McCloskey, Kathleen Malloy, Marilyn Sitaker, Nancy Grigsby, and Paulette Gillig. 2004. "Humiliation, Manipulation, and Control: Evidence of Centrality in Domestic Violence Against an Adult Partner." Journal of Family Violence 19:339-354.

Straus, Murray A. 1979. "Measuring Intrafamily Conflict and Violence: The Conflict Tactics (CT) Scales." Journal of Marriage and Family 41:75-88.

Testa, Maria, Brian M. Quigley, and Kenneth E. Leonard. 2003. “Does Alcohol Make a Difference? Within-Participants Comparison of Incidents of Partner Violence." Journal of Interpersonal Violence 18:735-743.

Thompson, Martie P. and J. B. Kingree. 2006. “The Roles of Victim and Perpetrator Alcohol Use in Intimate Partner Violence Outcomes." Journal of Interpersonal Violence 21:163-177.

Tichenor, Veronica Jaris. 1999. "Status and Income as Gendered Resources: The Case of Marital Power." Journal of Marriage and Family 61:638-650.

Tichenor, Veronica Jaris. 2005. Earning More and Getting Less: Why Successful Wives Can't Buy Equality. New Brunswick, NJ: Rutgers University Press.

Tjaden, Patricia and Nancy Thoennes. 2000. "Prevalence and Consequences of Male-toFemale and Female-to-Male Intimate Partner Violence as Measures by the National Violence Against Women Survey." Violence Against Women 6:142-161.

Tolman, Richard M. and Larry W. Bennett. 1990. "A Review of Quantitative Research on Men Who Batter." Journal of Interpersonal Violence 5:87-118.

Tolman, Richard M. and Jody Raphael. 2000. “A Review of Research on Welfare and Domestic Violence." Journal of Social Issues 56:655-682.

Whaley, Rachel B. and Steven F. Messner. 2002. “Gender Equality and Gendered Homicides." Homicides Studies 6:188-210. 